\title{
HOMOFOBIA Y RECEPCIÓN DE PERSONAJES LÉSBICOS EN NARRATIVAS AUDIOVISUALES
}

\section{Homophobia and the Reception of Lesbian Characters in Audiovisual Narratives}

\section{Homofobia e recepção de personagens lésbicas em narrativas audiovisuais}

\author{
*Isabel Villegas-Simón, Universitat Autònoma de Barcelona (España) \\ isamarvillegas@gmail.com \\ Ariadna Angulo-Brunet, Universitat Autònoma de Barcelona (España) \\ ariadna.angulo@uab.cat \\ Kexin Liu, Universitat Autònoma de Barcelona (España) \\ liukexin1990@gmail.com
}

Recibido: 15 de julio de 2016

Aceptado: 23 de enero de 2017

\section{RESUMEN}

La presencia de personajes lésbicos ha aumentado en las narrativas audiovisuales populares, como en las series de televisión o las películas. Por ello es necesario explorar su percepción en audiencias heterogéneas. El objetivo de la investigación es explorar la relación entre la homofobia y la identificación con los personajes, el disfrute y el gusto como procesos de recepción narrativa en ficciones audiovisuales protagonizadas por lesbianas. Para ello, se ha realizado un trabajo empírico compuesto por un cuestionario en línea en el que 140 participantes contestaron primero a preguntas sobre su grado de homofobia, en segundo lugar realizaron un visionado y, finalmente, contestaron preguntas relativas a la identificación, el disfrute y el gusto. Tras obtener las evidencias de validez

* Envíese la correspondencia vinculada al texto a esta autora. 
de la escala de Homofobia Moderna de Lesbianas (MHS-L) se exploraron las relaciones entre las dimensiones de la escala y el resto de variables. Los principales resultados muestran que las personas que tienen un grado menor de homofobia institucional disfrutan en mayor medida y les gusta más el video. Asimismo, se evidenció que los hombres se identifican más intensamente con los personajes de lesbianas, y los gais y lesbianas disfrutan más. Estos resultados se interpretan a la luz de las teorías del entretenimiento mediático.

Palabras clave: homofobia, identificación con los personajes, recepción, psicología de los medios, lesbianas.

\begin{abstract}
The presence of lesbian characters has increased in popular audiovisual narratives such as television series and movies. It is therefore necessary to explore how they are perceived by heterogeneous audiences. The main goal of this research is to explore the relationship between homophobia, identification with characters, and enjoyment as processes of narrative reception in audiovisual fiction featuring lesbians. To do this, an empirical study was carried out, consisting of an online questionnaire in which 140 participants answered questions about their degree of homophobia. Then they watched prescribed television material and finally answered questions related to identification, enjoyment, and taste. After obtaining evidence of the validity of the Modern Homophobia Scale (MHS-L), the relationships between the scale's dimensions and other variables were explored. The primary results show that people who have a lower degree of institutional homophobia enjoy the video and like it more. Likewise, men identify more intensely with lesbian characters and gays and lesbians enjoy it more. These results are interpreted in the light of media entertainment theories.
\end{abstract}

Keywords: Homophobia, identification with characters, reception, media psychology, lesbians.

\title{
RESUMO
}

A presença de personagens lésbicas tem aumentado nas narrativas audiovisuais populares, como as séries de televisão ou os filmes. Por isso é necessário explorar sua percepção em audiências heterogêneas. 0 objetivo da pesquisa é explorar a relação entre a homofobia e a identificação com as personagens, o disfrute e o gosto como processos de recepção narrativa em ficções audiovisuais protagonizadas por lésbicas. Para isto, se tem realizado um trabalho empírico composto por um questionário online no que 140 participantes contestaram primeiro a perguntas sobre seu grau de homofobia, em segundo lugar realizaram um visionado e finalmente, contestaram perguntas relativas à identificação, o disfrute e o gosto. Após obter as evidências de validez da escala de Homofobia Moderna de Lésbicas (MHS-L) exploraram-se as relações entre as dimensões da escala e o resto de variáveis. Os principais resultados mostram que as personagens que têm um grau menor de homofobia institucional disfrutam em maior medida e gostam mais do vídeo. Igualmente, os homens identificam-se mais intensamente com as 


\section{DISERTACIONES}

ESTUDIOS

Estudios de audiencias y recepción: audiencias minoritarias y nuevas mediaciones

ISSN: 1856-9536

Doi: http://dx.doi.org/10.12804/revistas.urosario.edu.co/disertaciones/v11i1

Volumen 11, Número 1 / Enero-junio 2018

Versión PDF para imprimir desde

http://revistas.urosario.edu.co/index.php/disertaciones

personagens de lésbicas e os gays e lésbicas desfrutam mais. Estes resultados interpretam-se à luz das teorias do entretenimento mediático.

Palavras-chave: homofobia, identificação com as personagens, recepção, psicologia dos meios, lésbicas.

\section{Introducción}

En 1973, George Weinberg utiliza el término homofobia para describir el rechazo y desprecio hacia una persona en función de su identidad sexual. Con mayor profundidad, se define como el malestar personal causado por la sensación de incomodidad que genera estar en contacto con personas gais o lesbianas y/o la creencia que son personas enfermas y pervertidas (Hall, Kitzinger, Loulan \& Perkins, 1992; Raja \& Stokes, 1998). Rodríguez-Castro, Lameiras-Fernández, Carrera-Fernández \& Vallejo-Medina (2013) indican que este malestar personal puede oscilar entre sentimientos leves de rechazo hasta a un fuerte sentimiento de odio y miedo. En consecuencia, distinguen entre dos tipos de actitudes: latentes o sutiles, como las que se encuentran generalmente en los discursos culturales, políticos o médicos relativos al carácter patológico de la homosexualidad o el cuestionamiento de los homosexuales para realizar ciertas prácticas (la adopción, el matrimonio), y las segundas, explícitas u hostiles, como las agresiones físicas y psicológicas hacia las personas homosexuales.

Por su parte, Blumenfeld (1992) ha identificado cuatro niveles de homofobia: a) Personal, relativa a las creencias o prejuicios de un individuo; b) Interpersonal, cuando se ejerce la discriminación por los prejuicios; c) Institucional, referente a las instituciones públicas, privadas, religiosas o profesionales que realizan prácticas que excluyen a las personas homosexuales, y d) Social, relacionada con la manifestación y representación de la homofobia en los discursos y representaciones de la cultura popular. Los estudios precedentes que han explorado la relación entre la homofobia y otras variables han concluido que los individuos más homofóbicos tienden a profesar creencias autoritarias y restrictivas sobre la libertad individual (Smith, 1971; Wylie \& Forest, 1992), el conservadurismo sexual (Aguero, Bloch \& Byrne, 1984; Hudson \& Ricketts, 1980) y el fundamentalismo religioso (Agnew, Thompson, Smith, Gramzow \& Currey, 1993).

Diversos autores han sugerido que la homofobia presenta connotaciones políticas y sociales diferentes si es hacia los gais o hacia las lesbianas. Raja \& Stokes (1998) sugieren que los gais han estado más visibilizados y más castigados socialmente que las lesbianas. Faderman (1985) argumenta que históricamente las relaciones sentimentales entre mujeres han sido más aceptadas y permitidas puesto que no han supuesto una amenaza a la estructura de poder patriarcal. No fue sino hasta el siglo xx, con el auge de la lucha feminista, que el lesbianismo fue percibido como una amenaza a los privilegios de los hombres frente a las mujeres (Rodríguez-Castro et al., 2013).

Las diferencias en el tratamiento de gais y lesbianas en los medios de comunicación y de entretenimiento también han sido puestas de manifiesto (Carvalho, 2015). Tradicionalmente, los personajes homosexuales en las narrativas populares han sido caracterizados como enfermos, peligrosos, pecadores, amorales, infelices y marginales (Carvalho, 2015). La teoría queer utiliza el concepto "sexismo queer" para criticar la normalización que se ha hecho del discurso de la homosexualidad a partir de los gais, que margina los intereses y preocupaciones de 


\section{DISERTACIONES}

ESTUDIOS

Estudios de audiencias y recepción: audiencias minoritarias y nuevas mediaciones

ISSN: 1856-9536

Doi: http://dx.doi.org/10.12804/revistas.urosario.edu.co/disertaciones/v11i1

Volumen 11, Número 1 / Enero-junio 2018

Versión PDF para imprimir desde

http://revistas.urosario.edu.co/index.php/disertaciones

otras minorías sexuales y de grupos étnicos. Por su parte Collier, Lumadue y Wooten (2009) sugieren que tanto la televisión como internet se han utilizado para normalizar y visibilizar la experiencia de las lesbianas, mientras que Gónzalez de Garay (2009) señala cómo la incorporación de personajes lésbicos a las series televisivas está siendo exponencial, lo que hace pertinente estudiar su percepción social.

Soto-Sanfiel et al. (2011; 2014a; 2014b; 2016) han estudiado la recepción de contenidos audiovisuales protagonizados por lesbianas en audiencias de diferentes orientaciones sexuales. Soto-Sanfiel, Ibiti, Palencia-Villa y Velásquez (2011) exploran las reacciones psicológicas de las audiencias a narrativas de lesbianas desde una aproximación mixta (cualitativa y cuantitativa). Sus resultados muestran que aquellos que manifiestan una orientación sexual no normativa tienen actitudes más intensas y de mayor grado, independientemente de su género. También que las lesbianas frente a una narrativa protagonizada por lesbianas tienen reacciones más positivas e intensas que el resto. Por su parte, Soto-Sanfiel et al. (2014a) estudian la apreciación como proceso psicológico asociado a la recepción de contenidos lésbicos en audiencias con diversidad sexual y muestran que la orientación sexual influye en la apreciación de las narrativas lésbicas, donde las lesbianas son las que muestran mayor grado de apreciación que los gais o los que manifiestan una sexualidad normativa. Por otra parte, Soto-Sanfiel et al. (2014b) estudian el proceso de identificación con personajes lésbicos. Mientras que no encuentran que el género influya en el proceso de identificación, refutando a Eyal y Rubin (2003) y Maccoby y Wilson (1957), quienes consideraron que el género es un aspecto que afecta la identificación, las autoras sí detectan que la orientación sexual afecta la identificación: los gais y las lesbianas son quienes más se identifican, a diferencia del grupo con una sexualidad normativa. Soto-Sanfiel et al. (2014b) indican dos factores que lo explican: la resonancia personal que evocan las historias y la similitud de las historias con las experiencias propias. Las lesbianas se identifican más por la resonancia personal, mientras que, en el caso de los gais, es la similitud de la experiencia el principal motivo. Por tanto, llegan a afirmar que la orientación sexual es un aspecto que influye en el proceso de identificación. Sus resultados son coherentes con los trabajos precedentes que consideran que la similitud con los personajes y la resonancia personal afectan la identificación (Cohen, 2001; Eyal \& Rubin, 2003; Linné, 1975; Maccoby \& Wilson, 1957). Desde una perspectiva cualitativa y centrada en las audiencias lesbianas, Ibiti (2011) profundiza en la recepción de personajes lésbicos y concluye que las personas con actitudes más positivas hacia las lesbianas tienden a evaluar de forma más positiva a los personajes lésbicos. Por el contrario, no existe una relación entre la homofobia de la persona y la evaluación negativa del personaje. Finalmente, añade que las lesbianas tienden a identificarse con personajes lésbicos que no se ajustan a los roles femeninos tradicionales y que sean interpretados por actrices que se rumorea podrían ser lesbianas (Ibiti, 2011).

Centrándose en audiencias lesbianas, Ibiti (2013) explora los aspectos que les gustan a las lesbianas de los contenidos lésbicos y señala el realismo percibido, la identificación con los personajes y la apreciación como factores que influyen en las preferencias de la audiencia lesbiana. Posteriormente, Carvalho (2015) explora la influencia de la homofobia y la moralidad en la apreciación y el realismo percibido en narrativas lesbianas en audiencias de todas las orientaciones sexuales. Por un lado, encuentra que el género afecta las respuestas de la audiencia en la apreciación, la moralidad y el realismo percibido. No obstante, frente a los resultados de Soto-Sanfiel et al. (2014a; 2014b) y Soto-Sanfiel e Ibiti (2016), quienes sí encontraron que la orientación sexual influye en las respuestas de las audiencias, donde los gais y lesbianas son los que muestran actitudes más positivas e intensas que los que manifiestan una sexualidad normativa, Carvalho (2015) no encuentra diferencias. En una investigación más reciente sobre la recepción de escenas 


\section{DISERTACIONES}

ESTUDIOS

Estudios de audiencias y recepción: audiencias minoritarias y nuevas mediaciones

ISSN: 1856-9536

Doi: http://dx.doi.org/10.12804/revistas.urosario.edu.co/disertaciones/v11i1

Volumen 11, Número 1 / Enero-junio 2018

Versión PDF para imprimir desde

http://revistas.urosario.edu.co/index.php/disertaciones

de sexo explícito lésbico, Soto-Sanfiel e Ibiti (2016) encontraron que este tipo de escenas generan sensaciones placenteras que aumentan el disfrute en las audiencias de todas las orientaciones sexuales.

El conjunto de estas investigaciones precedentes sugiere que las audiencias, independientemente de su orientación sexual, gustan de las historias con lesbianas como protagonistas. Además constatan que ambos constructos, el disfrute y el gusto, influyen en la identificación con los personajes, la apreciación y el enganche narrativo. Además, se ha puesto de manifiesto que la identificación con los personajes es un factor relevante en la recepción de narrativas audiovisuales protagonizadas por lesbianas (Ibiti, 2011; Soto-Sanfiel et al, 2014b). De forma más específica, Ibiti (2011) y Soto-Sanfiel et al. (2014b) concluyen que las audiencias valoran más los personajes lésbicos por sus actitudes morales y conducta que por su orientación sexual. Hecho que las autoras encuentran coherente con la teoría de la disposición del afecto, que postula que si los espectadores consideran las acciones y motivaciones de los personajes moralmente correctas forman disposiciones afectivas positivas hacia estos.

Esta investigación se plantea seguir profundizando en la identificación con personajes lésbicos de las ficciones audiovisuales populares. Concretamente, plantea explorar cómo las actitudes homófobas afectan el proceso de identificación con los personajes, así como continuar con la investigación abierta por Carvalho (2015), quien estudia la relación entre la homofobia y la apreciación y el realismo percibido. Junto con la identificación de los personajes, también se estudian el disfrute y el gusto, dos de los constructos más importantes en las respuestas de las audiencias a los productos de entretenimiento (Vorderer, Klimmt \& Ritterfeld, 2004).

\section{Identificación con los personajes}

La identificación con los personajes tiene su origen en el psicoanálisis (Igartua \& Muñiz, 2008) y posee una amplia trayectoria en la investigación sobre el entretenimiento mediático. Sin embargo, su constatación empírica ha sido escasa, así como su conceptualización, sus dimensiones básicas y su diferenciación respecto a otros constructos afines (Eyal \& Rubin, 2003; Maccoby \& Wilson, 1957). Cohen, (2001) define la identificación con los personajes como un proceso imaginativo por el que los espectadores asumen la identidad, objetivos y perspectivas de un personaje desde el punto de vista afectivo y cognitivo. Hace énfasis en afirmar que la identificación no es una actitud, una emoción o una percepción, sino un proceso psicológico que consiste en la pérdida de la consciencia propia y su reemplazo por la de un personaje. Igartua y Muñiz (2008) señalan que la audiencia puede experimentar situaciones alternativas a su vida cotidiana con objetivos, sentimientos y pensamientos diferentes.

Cohen (2001), basándose en la literatura precedente sobre la relación de la audiencia con los personajes, elabora las siguientes hipótesis: a) los géneros narrativos provocarán una mayor identificación que los no-narrativos al proporcionar una realidad alternativa conocida por la audiencia; b) la similitud entre la audiencia y los personajes incrementará la identificación y la similitud basada en múltiples factores: demográficos, por atributos o por situaciones; c) la familiaridad con el personaje aumenta la identificación; d) la percepción de realismo del personaje también mejorará la identificación -el realismo no tiene por qué ser como la vida real, sino que puede remitir a un estereotipo de un grupo social-, y e) las variables psicológicas también influyen en la relación con los personajes, como los modelos de fijación y de autoestima.

En relación con las narrativas audiovisuales, se ha sugerido que el proceso de identificación puede darse por un recurso narrativo que muestre el punto de vista del personaje (Wilson \& Bickley, 1993) por la atracción hacia un

\section{4}




\section{DISERTACIONES}

ESTUDIOS

Estudios de audiencias y recepción: audiencias minoritarias y nuevas mediaciones

ISSN: 1856-9536

Doi: http://dx.doi.org/10.12804/revistas.urosario.edu.co/disertaciones/v11i1

Volumen 11, Número 1 / Enero-junio 2018

Versión PDF para imprimir desde

http://revistas.urosario.edu.co/index.php/disertaciones

personaje, ya sea por su atractivo físico o unas características de personalidad favorables (Cohen, 2001), o por una relación de similitud entre los espectadores y el personaje (Maccoby \& Wilson, 1957). Dentro de la investigación empírica, se han determinado una serie de factores que influyen en el proceso de identificación que son la construcción de los textos en los que intervienen aspectos narrativos y de producción, las características de la audiencia -conocimiento previo de situaciones o personajes, expectativas hacia los mismo o factores evolutivos-, el diseño de los personajes - apariencia física, rasgos de personalidad, modos de habla, tipo de conducta, estados emocionales y comportamientos no verbales-y el contexto de recepción -en una sala de cine, en el hogar...(Calvert, Murray \& Conger, 2004; Chory-Assad \& Cicchirillo, 2005; Cohen, 2001; Hoffner \& Cantor, 1991).

Al mismo tiempo, la identificación con los personajes se considera como un elemento esencial para comprender el impacto de las ficciones en las audiencias (Igartua \& Muñiz, 2008), una variable crucial en los estudios de recepción del entretenimiento mediático, de medios convencionales e interactivos y un predictor en el enganche narrativo (Cohen, 2001; Soto-Sanfiel, Aymerich-Franch \& Ribes Guàrdia, 2010).

La identificación con los personajes ha sido considerada un proceso relevante en el impacto de los medios. Cohen (2001) sugiere que dicho impacto se debe al papel que desempeña la identificación dentro de la socialización y de las teorías de la persuasión. Igartua y Muñiz (2008) señalan cómo la identificación con los personajes incide en la influencia que tienen los contenidos violentos en los comportamientos agresivos de los espectadores. También se ha señalado cómo dentro de las investigaciones sobre el entretenimiento mediático, la identificación con los personajes afecta a los procesos de inducción afectiva (Davis \& Hull, 1987; Igartua \& Muñiz, 2008; Wied, Zillmann \& Ordman, 1994).

Cohen (2001) sugiere que la identificación puede incrementar la implicación con el mensaje y estimular la elaboración cognitiva. Al mismo tiempo, autores como Slater \& Rouner (2002) concluyen que la identificación con los personajes puede tener un impacto persuasivo incidental que puede suprimir los procesos de contrargumentación. En esta línea, Igartua et al. $(2007 ; 2011 ; 2012)$ han explorado el rol de la identificación con los personajes y la persuasión narrativa. También se ha manifestado que la identificación con los personajes es un factor importante en el disfrute de la película. Para Wied et al. (1994) la identificación con los personajes está relacionada con la empatía que generan, a su vez el grado de empatía está vinculado con el disfrute de una película. Por tanto, cuanto mayor sea la empatía, mayor será la identificación y el disfrute. Igartua y Muñiz (2008) constataron que la empatía es una variable relevante que puede explicar el grado de identificación con los espectadores y que esta es la variable principal en la explicación del disfrute. Los autores también señalaron otras variables que afectan a la identificación, específicamente la resonancia personal y la cercanía cultural. Explican cómo ambas facilitan la recepción afectiva a través de la evocación emocional y de acceso a recuerdos y acontecimientos autobiográficos. Finalmente, Soto-Sanfiel et al. (2014a; 2014b) en sus trabajos sobre el proceso de identificación con personajes lésbicos concluyen que la identificación no es automática con el personaje principal, sino que es selectiva y orientada.

Para Cohen (2001) un teoría de la identificación debe incluir presunciones y características de las narrativas ya que diferentes tipos de textos provocan diferentes respuestas en las audiencias, y añade que la apropiación y recepción variará en función del grupo social y de las variables psicológicas de los individuos. El mismo autor también ha afirmado que al ser la identificación un proceso imaginativo que se caracteriza por alterar el estado de consciencia es difícil de medir. Respecto a las escalas de identificación, Cohen (2001) considera que uno de los 


\section{DISERTACIONES}

ESTUDIOS

Estudios de audiencias y recepción: audiencias minoritarias y nuevas mediaciones

ISSN: 1856-9536

Doi: http://dx.doi.org/10.12804/revistas.urosario.edu.co/disertaciones/v11i1

Volumen 11, Número 1 / Enero-junio 2018

Versión PDF para imprimir desde

http://revistas.urosario.edu.co/index.php/disertaciones

problemas es que muchos investigadores han utilizado ítems similares para medir tanto la identificación como otros procesos de las audiencias: la interacción parasocial, la imitación o la similitud.

El autor afirma que estos procesos no pueden ser considerados idénticos y sugiere que para medir la identificación hay que tener en cuenta algunos factores como: a) identificar o compartir los sentimientos del personaje; b) asumir su perspectiva o entender las motivaciones de su comportamiento; c) revelar hasta qué punto la audiencia entiende los objetivos del personaje, y d) conocer en qué medida la audiencia pierde la noción de sí misma para sentirse como el personaje. Añade que la identificación debe ser medida en relación a la frecuencia y la intensidad. Sin llegar a validarla, propone una escala de 10 ítems que tienen en cuenta estas 4 dimensiones, que posteriormente fue validada por Chory-Assad y Cicchirillo (2005) con la audiencia televisiva.

Dentro del contexto español, Igartua y Páez (1998) crearon y validaron la "Escala autoaplicada de identificación con los personajes del relato audiovisual de ficción" conformada por 17 ítems. Más tarde, fue validada por Soto-Sanfiel et al. (2010) para medir la identificación en ficciones interactivas. En esta última investigación, los autores propusieron que la escala debería aplicarse a personajes específicos y obtuvieron resultados ligeramente diferentes, puesto que hallaron la existencia de solo dos factores: el sentimiento de volverse el personaje y la empatía cognitiva-emocional. Recogiendo las propuestas de estos últimos, Igartua, Barrios y Piñeiro (2011) proponen una versión reducida de la escala con solo 11 ítems y sugieren que la identificación con los personajes es un factor latente y está explicada por otros tres -empatía cognitiva, empatía emocional y sensación de volverse el personaje-. Con empatía emocional se hace referencia a la implicación afectiva que siente la audiencia con los personajes, sentirse preocupado por lo que les pasa y sus problemas. Respecto a la empatía cognitiva, se trata de la capacidad de entender a los personajes y adoptar su perspectiva; imaginar cuáles son sus pensamientos, sentimientos y estados mentales, y cuáles pueden ser sus consecuencias. Finalmente, volverse el personaje, describe la pérdida de autoconsciencia para sentirse como si se fuera el personaje y vivir la historia como si se estuviera dentro de ella. En esta misma investigación, los autores sugieren como indicador de la identificación una suma de las puntuaciones obtenidas en los 11 ítems: se obtiene así una medición global, entendiendo que a mayor puntuación mayor identificación con el personaje.

\section{Escala de homofobia}

Dado que el objetivo principal es explorar cómo influyen las actitudes homófobas en la identificación con los personajes, a continuación se detalla cómo se mide la homofobia. Como señalan Rodríguez-Castro et al. (2013), desde los años setenta han surgido diferentes escalas para medir la homofobia (Smith, 1971; Hudson \& Ricketts, 1980; Larsen, Reed \& Hoffman, 1980; Aguero et al., 1984; Hansen, 1982; Wright, Adams \& Bernat, 1999; Raja \& Stoker, 1998), que han perseguido un doble objetivo: por un lado contemplar las actitudes homofóbicas explícitas y sutiles, y por otro lado, evaluar las actitudes hacia los gais y las lesbianas de forma separada.

Raja y Stokes (1998) proponen la Escala de Homofobia Moderna en la que recogen los cambios de las últimas décadas. Está compuesta por dos escalas: actitudes hacia los gais (MHS-G, por sus siglas en inglés: Modern Homophobia Scale - Gays) y actitudes hacia las lesbianas (MHs-L, por sus siglas en inglés: Modern Homophobia Scale Lesbians). Cada una de estas escalas mide a su vez tres subescalas: homofobia institucional, malestar personal y desviación/cambiabilidad. 


\section{DISERTACIONES}

ESTUDIOS

Estudios de audiencias y recepción: audiencias minoritarias y nuevas mediaciones

ISSN: 1856-9536

Doi: http://dx.doi.org/10.12804/revistas.urosario.edu.co/disertaciones/v11i1

Volumen 11, Número 1 / Enero-junio 2018

Versión PDF para imprimir desde

http://revistas.urosario.edu.co/index.php/disertaciones

La homofobia institucional es la creencia de que las prácticas a nivel gubernamental, empresarial, religioso o profesional deben estar exentas de un sesgo por orientación sexual. Por su parte, el malestar personal se define como la necesidad de evitar el contacto con homosexuales a causa de una sensación de incomodidad por la presencia de homosexuales o la creencia de que la homosexualidad es una enfermedad. Finalmente, la desviación/ cambiabilidad se entiende como el pensamiento que los homosexuales pueden cambiar su orientación sexual cuando quieran. Puntuaciones más altas en homofobia institucional o malestar personal se asemejan a una actitud más positiva hacia la homosexualidad, en cambio, en desviación/cambiabilidad las puntuaciones más altas responden a una actitud negativa hacia la homosexualidad.

Rodríguez-Castro et al. (2013) obtienen evidencias de validez para ambas escalas en el contexto español (MHS-G y MHS-L) en adolescentes y buenos ajustes acordes con el modelo trifactorial propuesto por los autores originales. Por su parte, Carvalho (2015) incorpora a la escala de homofobia moderna hacia las lesbianas en español 10 ítems sobre normas sociales para las lesbianas y 3 que miden la moralidad neutral de la escala de LaMar y Kite (1998). A partir de sus resultados propone siete factores en lugar de los tres de la escala original.

Los estudios realizados con la mHs en el contexto español por Rodríguez-Castro et al. (2013) revelan que los chicos presentan actitudes más discriminatorias hacia los gais que hacia las lesbianas, y que las chicas manifiestan actitudes menos homofóbicas hacia ambos colectivos. También constatan que los chicos tienen actitudes más positivas hacia las lesbianas que hacia los gais en las tres subescalas. Por su parte, las chicas tienen actitudes más negativas hacia las lesbianas que hacia los gais, excepto en la subescala de desviación/cambiabilidad. Estos resultados concuerdan con los estudios precedentes realizados tanto en adolescentes, como en adultos (Hill \& Willoughby, 2005; Lingiardi, Falanga \& D’Augelli, 2005; Raja \& Stokes, 1998). El hecho de que los chicos tengan una actitud más favorable hacia las lesbianas que hacia los gais puede justificarse por la erótica lesbiana que caracteriza a la sociedad patriarcal y la cultura masculina (Rodríguez-Castro et al., 2013). Carvalho (2015) no encontró relación entre el género y las actitudes hacia las lesbianas. Tampoco encontró que la orientación sexual influyera en las actitudes generales hacia las lesbianas o hacia las respuestas de la narrativa audiovisual protagonizada por lesbianas. Refuta la idea de que las personas tienden a ser más homofóbicas hacia los homosexuales de su propio género (Herek \& Capitanio, 1995; Kite \& Whitley, 1996; Kite, 1987) o que los hombres son más homofóbicos que las mujeres (Raja \& Stokes, 1998; Rodríguez-Castro et al., 2013). Dadas las incongruencias encontradas en Carvalho (2015) en relación con la literatura precedente, se considera oportuno obtener evidencias de validez del constructo para adultos españoles.

\section{Hipótesis y objetivos}

En el estudio se plantea un doble objetivo general. Por un lado, se quieren obtener evidencias de validez y fiabilidad para la escala mHs-L en adultos dentro del contexto español. Este objetivo está motivado porque la adaptación del cuestionario original de Raja y Stokes (1998) al contexto español se hizo con adolescentes (Rodríguez-Castro et al. 2013). Aunque Carvalho (2015) realiza una propuesta en adultos, sus resultados no confirman la estructura de la escala original puesto que obtiene siete factores en lugar de tres. Por tanto, se considera necesario obtener evidencias que confirmen la escala original de tres dimensiones. Como segundo objetivo se plantea observar el fenómeno de la identificación con los personajes en el consumo de narrativas audiovisuales protagonizadas por personajes lésbicos. Específicamente, se busca explorar la relación con la homofobia, el género del receptor (hombres y mujeres) y la 


\section{DISERTACIONES}

ESTUDIOS

Estudios de audiencias y recepción: audiencias minoritarias y nuevas mediaciones

ISSN: 1856-9536

Doi: http://dx.doi.org/10.12804/revistas.urosario.edu.co/disertaciones/v11i1

Volumen 11, Número 1 / Enero-junio 2018

Versión PDF para imprimir desde

http://revistas.urosario.edu.co/index.php/disertaciones

orientación sexual manifiesta (normativa y no normativa). Teniendo presente la literatura precedente y los objetivos marcados, se establecen las siguientes hipótesis:

H1a: El género del receptor no influirá en las actitudes homofóbicas hacia las lesbianas.

H1b: La orientación sexual del receptor no influirá en las actitudes homofóbicas hacia las lesbianas. Siguiendo principalmente a Carvalho (2015) quien refuta esta idea de estudios precedentes que afirman que la homofobia es mayor entre personas del mismo género y que los hombres son más homofóbicos. Además, que la orientación sexual no afecta a la homofobia.

H2: No existirán diferencias en la identificación según el género del receptor. Esta hipótesis se marca en relación con Soto-Sanfiel et al. (2014a), quienes no encontraron diferencias entre hombres y mujeres en la identificación.

H3: Existirán diferencias en la identificación en función de la orientación sexual. En particular, los homosexuales se identificarán más que los heterosexuales, en concordancia con los resultados de Soto-Sanfiel et al. (2014b), quienes afirman que la orientación sexual es un factor que influye en la identificación con los personajes.

H4: Los sujetos con actitudes más positivas hacia las lesbianas tenderán a una mayor identificación. Teniendo presentes los resultados de Carvalho (2015), quien encuentra que las personas menos homofóbicas tienden a evaluar mejor las cualidades de los personajes lésbicos, mientras que no encuentra una relación tan fuerte entre las personas más homofóbicas y la evaluación negativa de los personajes lésbicos.

H5: El género y la orientación sexual no afectarán el disfrute o el gusto. Siguiendo la tesis de Soto-Sanfiel et al. (2011, 2014a, 2014b) que afirman qua las audiencias pueden disfrutar y gustar de las historias con protagonistas lesbianas independientemente de su orientación sexual y género.

\section{Método}

\section{Participantes}

Un total de 140 personas (60\% mujeres) tomaron parte en el estudio. Los participantes tenían edades comprendidas entre los 19 y los 57 años ( $M=29,66 ; S D=8,9)$. El 80\% de las personas participantes manifestó ser heterosexual y el $20 \%$ manifestó tener orientaciones sexuales no normativas $(n=28)$. Así: 9 participantes dijeron que eran gais, 10 lesbianas y 9 bisexuales.

\section{Instrumentos}

El cuestionario estaba compuesto por diferentes secciones: variables sociodemográficas (edad, género y orientación sexual), la escala de homofobia moderna de lesbianas (MHS-L), la escala de identificación, una pregunta sobre el disfrute y otra sobre el gusto.

- MHS-L: propuesta por Raja y Stokes (1998), adaptada al español por Rodríguez-Castro et al. (2013) en adolescentes. La escala tiene tres factores: homofobia institucional, malestar personal y desviación/cambialidad. La homofobia institucional $(\alpha=, 83)$ tiene 11 ítems (ejemplo: "Los profesores deberías tratar de reducir los prejuicios de los estudiantes hacia las lesbianas" o "Las lesbianas que adoptan niños/as no deberías ser más controladas que los padres y madres heterosexuales"). El malestar personal $(\alpha=, 90)$ por su parte tiene relación con: "No me importa ver a dos chicas cogidas de la mano" o "No me molestaría que mi mejor amiga estuviera saliendo con una 


\section{DISERTACIONES}

ESTUDIOS

Estudios de audiencias y recepción: audiencias minoritarias y nuevas mediaciones

ISSN: 1856-9536

Doi: http://dx.doi.org/10.12804/revistas.urosario.edu.co/disertaciones/v11i1

Volumen 11, Número 1 / Enero-junio 2018

Versión PDF para imprimir desde

http://revistas.urosario.edu.co/index.php/disertaciones

chica". Finalmente, la desviación/cambiabilidad $(\alpha=, 90)$ tiene tres ítems ("Las lesbianas deberían recibir terapia para cambiar su orientación sexual"). La escala tiene un formato de respuesta en escala Likert, en la que 1 corresponde a totalmente en desacuerdo, y 5 a totalmente de acuerdo.

- Escala de Identificación (EDI): Escala de 11 ítems tipo Likert, validada por Igartua, Barrios y Piñeiro (2011). La escala está compuesta por tres factores: 1 ) empatía cognitiva $(\alpha=, 68)$, formada por cuatro ítems (ejemplo: "He imaginado cómo actuaría yo si me encontrara en el lugar de Tina"); 2 ) empatía emocional ( $\alpha=, 93)$ compuesta por tres ítems (ejemplo: "Me he sentido implicado/a afectivamente con los sentimientos de Tina"), y 3) la sensación de volverse el personaje $(\alpha=, 83)$ con tres ítems (ejemplo: "He tenido la impresión de vivir realmente yo mismo la historia de Tina"). La escala tiene un índice global de identificación a partir de la suma de todos los ítems.

- Disfrute y gusto: Un único ítem por cada concepto "He disfrutado la película" y "Me ha gustado la película". Tal y como previamente hicieron Igartua y Muñiz (2008) y Soto-Sanfiel et al. (2011).

Como estímulo se usó The $L$ Word (2004-2009), una de las primeras series de televisión norteamericanas protagonizada por personajes lésbicos. Se trata de una serie norteamericana producida por Showtime, que cuenta con 70 episodios. En España se emitió solo la primera temporada de 12 episodios en 2007 por Canal+. El fragmento que se utilizó fue producido a partir de la primera temporada de la serie. Con una duración de 13:39 minutos, a partir de la recopilación de las escenas relacionadas con la trama Tina. Con un planteamiento narrativo clásico, presenta temas susceptibles en torno a cuestiones sobre homofobia hacia las lesbianas. Se cuenta la historia de Tina, una mujer que decide dejar su carrera laboral para centrarse en tener un hijo junto con su pareja Bette. Tras intentar varios métodos, ambas deciden buscar un donante que insemine de forma artificial a Tina. La búsqueda del donante se complica por el rechazo de Bette a varios candidatos. Tina no logra comprender la actitud de Bette, y tras las opiniones negativas de sus amistades y el médico, que incluso llegan a situar el problema en que son lesbianas, decide replantearse su relación con Bette y tener el hijo sola. Finalmente, Bette le pide disculpas, acepta a uno de los donantes y Tina queda embarazada.

\section{Diseño y procedimiento}

Se realizó un diseño de investigación transversal con la finalidad de estudiar las variables de interés. Se contactó con los participantes mediante la difusión del cuestionario en redes sociales y correo electrónico, fundamentalmente. El cuestionario, que contó con cuatro partes, fue suministrado en línea a través de la plataforma Fluidsurveys. Para evitar datos perdidos era obligatorio responder a todos los campos.

En primer lugar, se informaba a los participantes de los objetivos del estudio y la confidencialidad y anonimato de su participación. Se indicaba que la duración aproximada de la prueba era de 20 minutos y que debía realizarse la tarea sin interrupciones y en soledad. Asimismo, se les indicaba que no había preguntas correctas o incorrectas, solo opiniones. También se recomendaba apagar aparatos que pudieran interferir en la comprensión de o en la atención a la película. Los participantes, tras aceptar participar, debían contestar las preguntas relativas a los datos sociodemográficos y la mнs-L. En la tercera fase, realizaban el visionado del fragmento seleccionado. Finalmente, debían responder a las escalas de identificación, disfrute y gusto. 


\section{Análisis Estadístico}

Se realiza mediante el programa libre $\mathrm{R}$, los estadísticos descriptivos y frecuencias para describir la muestra. Primero, se analizan la distribución de respuestas y las frecuencias, y se estudian los casos faltantes para determinar que estimador usar. Mediante el paquete LAVAan (Rosseel, 2012) se efectuó un análisis factorial confirmatorio (AFC) para obtener evidencias de validez interna del cuestionario con el estimador DwLS (por sus siglas en inglés Diagonally Weighted Least Squares). Finalmente, mediante el paquete semTools (2016) se obtuvo el coeficiente de fiabilidad más adecuado para el modelo de medida (Zinbarg, Revelle, Yovel \& Li, 2005).

Para los resultados entre las distintas variables de interés, y debido al efecto techo detectado en la muestra, no podemos asumir que los datos estén distribuidos normalmente y por lo tanto es pertinente el uso de técnicas no paramétricas. Por ello, mediante el contraste $U$ de Mann-Whitney se compararon dos variables independientes (género: hombre y mujer, y orientación sexual: normativa y no normativa). Además, se examinó la relación entre las escalas de ambos cuestionarios con la correlación de Pearson ( $r$ ). Finalmente, se midió el tamaño del efecto de las variables con diferencias estadísticamente significativas mediante la $r$ propuesta por Cohen (1988). Siguiendo las recomendaciones de Fritz, Morris y Richler (2012), este coeficiente fue obtenido análogamente a partir de la Z que ofrece el output de R.

\section{Software}

El análisis descriptivo y los contrastes U de Mann-Whitney se realizaron mediante sPss V21.00 para Mac y R. El análisis confirmatorio se realizó con el software libre R.

\section{Resultados}

\section{Análisis factorial confirmatorio de MHS-L}

El modelo de tres factores propuesto en el AFC (modelo 1) a partir de la solución factorial propuesta en Raja y Stokes (1998) y su adaptación al español por Rodríguez-Castro et al. (2013) de la escala de MHS-L presenta buenos índices de ajuste $\left(\alpha^{2}=124,886,=1,00, \mathrm{~g} . \mathrm{l}=248\right.$, un $\mathrm{CFI}=1,00$, TLI = 1,00, RMSEA = 0,00). En la figura 1, podemos encontrar el modelo estandarizado. Tal y como se puede observar, el ítem 1 (“Los empresarios deberían proporcionar un seguro médico para las parejas de sus empleadas lesbianas") y el 3 ("Las lesbianas que adoptan niños/as no deberían ser más controladas que los padres y madres heterosexuales”) tienen cargas factoriales inferiores a 0,3, además estos ítems explican menos de un $5 \%$ de la varianza del factor. 


\section{DISERTACIONES}

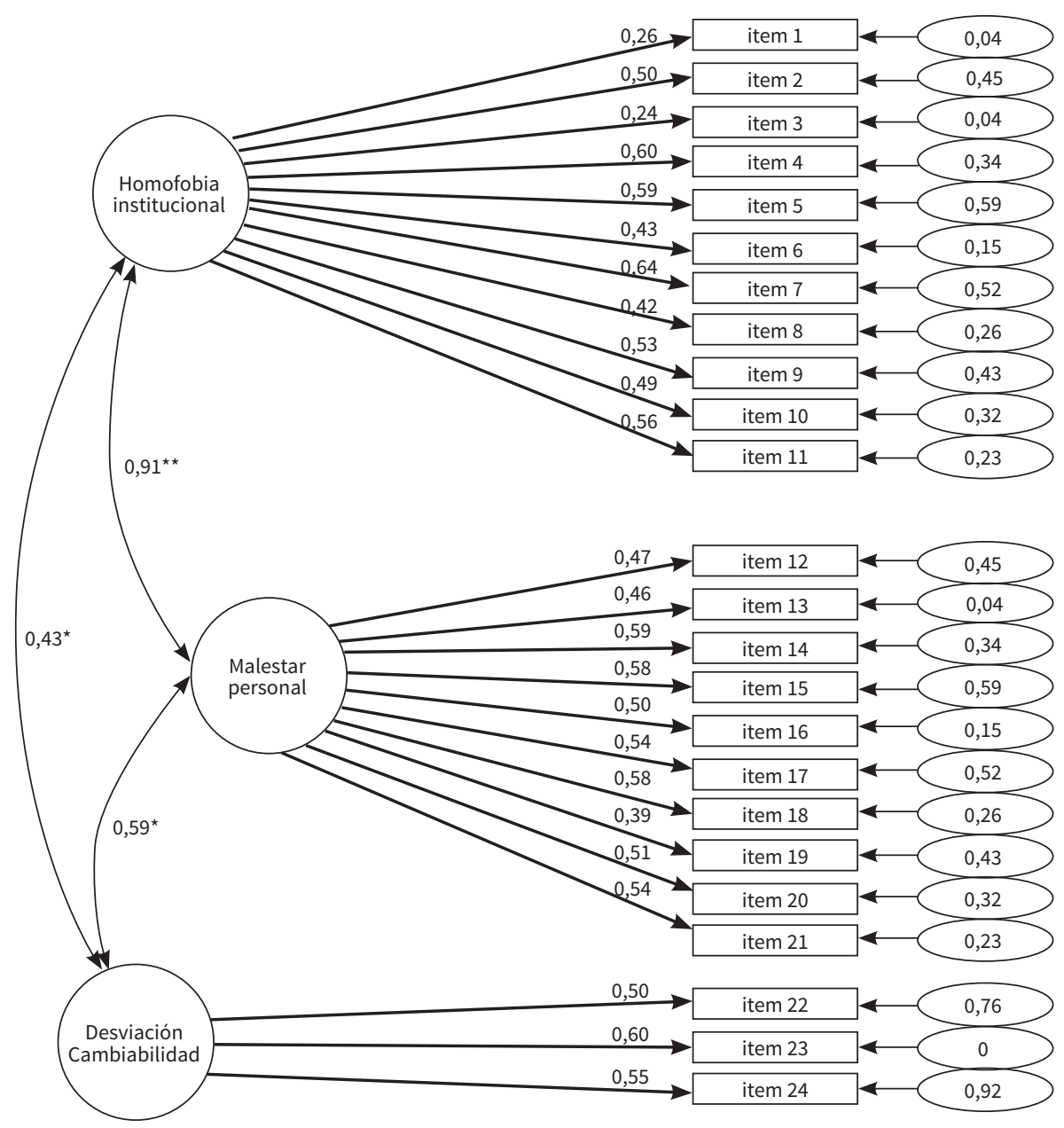

Figura 1. Análisis Factorial Confirmatorio modelo 1.

Nota: Círculos grandes variables latentes; rectángulos variables observadas; elipses varianzas residuales. ${ }^{\star} p<0,05 ;{ }^{* \star} p<0,001$

La revisión del contenido del ítem 1 , en el contexto cultural en el que se encuentra el presente trabajo, puede no estar representando por la institución de este país. Actualmente las empresas españolas, al contrario que las estadounidenses no acostumbran ofrecer un seguro médico a las parejas de los trabajadores, sea cual sea su condición sexual. Se decide incluir el ítem adoptar aunque tenga cargas factoriales bajas y se genera un segundo modelo (figura 2) que excluye el ítem empresarial del análisis. El modelo 2, al igual que el 1, presenta buenos índices de ajuste $\left(\chi^{2}=92,045, p=1,00, g . l=227, C F I=1,00, T L I=1,00\right.$, RMSEA $\left.=0,00\right)$. Igual que el modelo 1 , la carga factorial para el ítem adoptar es inferior a 0,3 y la varianza explicada inferior al 5\%. El ítem terapia también explica 


\section{DISERTACIONES}

Estudios de audiencias y recepción: audiencias minoritarias y nuevas mediaciones

ISSN: 1856-9536

Doi: http://dx.doi.org/10.12804/revistas.urosario.edu.co/disertaciones/v11i1

Volumen 11, Número 1 / Enero-junio 2018

Versión PDF para imprimir desde

http://revistas.urosario.edu.co/index.php/disertaciones

una parte muy pequeña de la varianza del factor desviación. Aún se decide conservar los dos ítems siguiendo la propuesta de los autores originales (Raja \& Stokes, 1998).

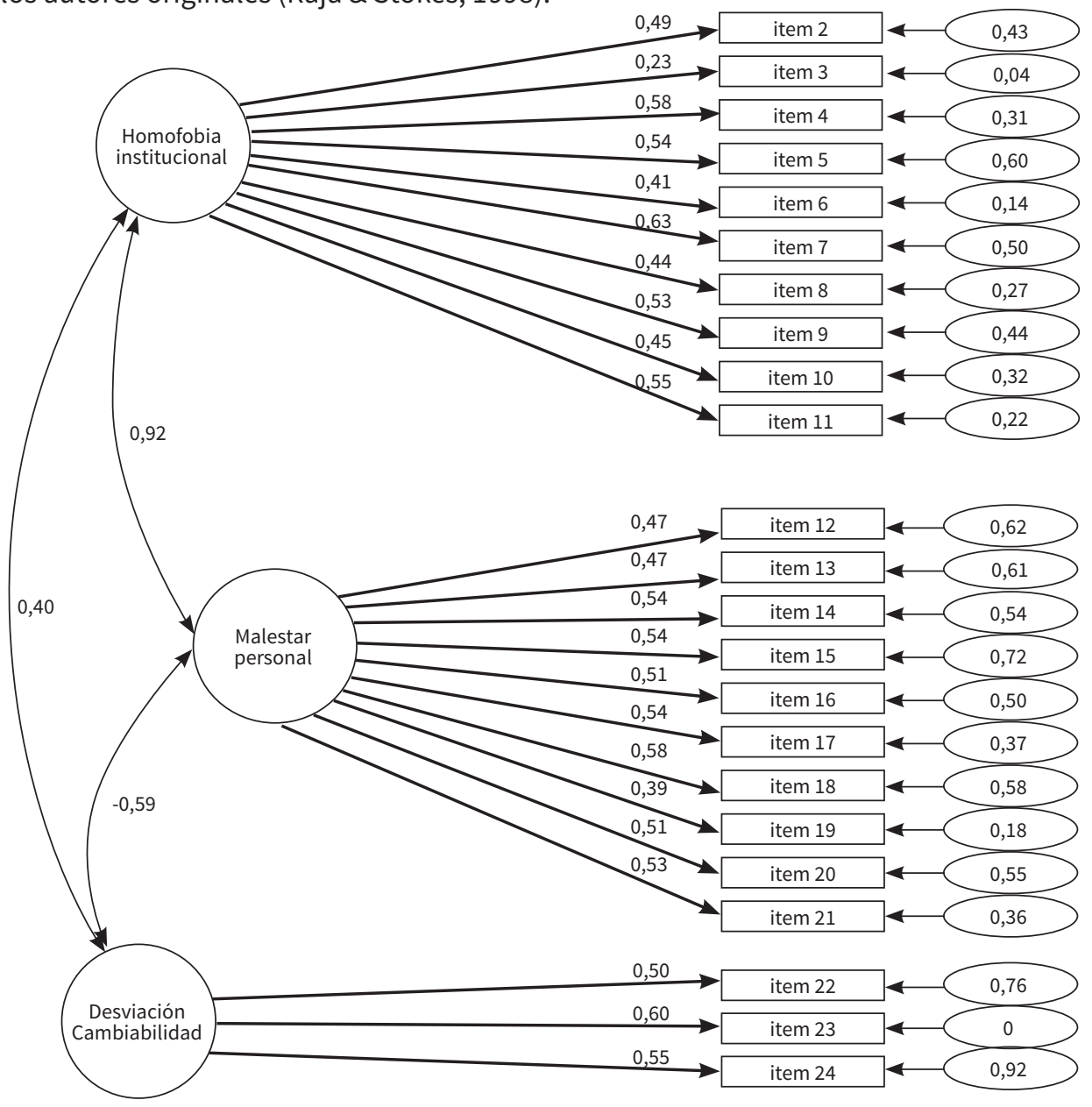

Figura 2. Análisis Factorial Confirmatorio modelo 2

Nota: Círculos grandes variables latentes; rectágulos variables observadas; elipses varianzas residuales. ${ }^{*} p<0,05 ;{ }^{* \star} p<0,001$

Finalmente, y vista la alta correlación entre los tres factores, se genera un modelo jerárquico (modelo 3). La solución factorial propuesta muestra un buen ajuste $\left(\chi^{2}=126,93, p=1,00, \mathrm{~g} . \mathrm{l}=249, \mathrm{CFI}=1,00, \mathrm{TLI}=1,00\right.$, RMSEA $\left.=0,00\right)$ pero no converge. Por lo tanto no hay evidencias de estructura interna con la muestra utilizada que soporten una puntuación total en esta escala.

Dados los resultados del AFC y considerando un modelo congenérico se utiliza el coeficiente omega de fiabilidad (Zinbarg et al. 2005). A continuación (tabla 1) se adjuntan los estadísticos descriptivos, así como el coeficiente de fiabilidad omega para todas las subescalas del cuestionario de MHs-L. Como se puede observar, los participantes han 


\section{DISERTACIONES}

ESTUDIOS

Estudios de audiencias y recepción: audiencias minoritarias y nuevas mediaciones

ISSN: 1856-9536

Doi: http://dx.doi.org/10.12804/revistas.urosario.edu.co/disertaciones/v11i1

Volumen 11, Número 1 / Enero-junio 2018

Versión PDF para imprimir desde

http://revistas.urosario.edu.co/index.php/disertaciones

tenido puntuaciones promedio muy elevadas. Como se deriva de la asimetría y curtosis hay un marcado efecto techo en las tres dimensiones.

Tabla 1. Estadísticos descriptivos y coeficiente de fiabilidad

\begin{tabular}{|c|c|c|c|c|c|c|c|}
\hline & M & SD & Mdn & range & a & c & ( \\
\hline Homofobia Institucional & 4,36 & 0,57 & 4,50 & 3,60 & $-1,61$ & 4,64 & 0,78 \\
\hline Malestar & 4,67 & 0,54 & 4,90 & 3,90 & $-2,99$ & 13,24 & 0,89 \\
\hline Desviación & 4,86 & 0,56 & 5,00 & 4,00 & $-5,40$ & 31,80 & 0,97 \\
\hline
\end{tabular}

Nota: Mdn = mediana; range = rango de puntuaciones; $a$ = asimetría; $c$ = curtosis; $\omega=$ omega total

\section{Género y orientación sexual}

En la tabla 2 pueden encontrarse el test U de Mann-Whitney para género y para orientación sexual.

Tabla 2. Pruebas U Mann-Whitney para género y orientación sexual y el resto de variables dependientes

\begin{tabular}{|c|c|c|c|c|c|c|c|c|c|c|c|c|c|c|}
\hline & \multicolumn{2}{|c|}{$\begin{array}{l}\text { Hombre } \\
(n=56)\end{array}$} & \multicolumn{2}{|c|}{$\begin{array}{l}\text { Mujer } \\
(n=84)\end{array}$} & \multirow[b]{2}{*}{$\mathbf{U}$} & \multirow[b]{2}{*}{$\mathbf{P}$} & \multirow[b]{2}{*}{$\mathbf{r}$} & \multicolumn{2}{|c|}{$\begin{array}{c}\text { Normativa } \\
(n=112)\end{array}$} & \multicolumn{2}{|c|}{$\begin{array}{c}\text { No } \\
\text { normativa } \\
(n=28)\end{array}$} & \multirow[b]{2}{*}{$\mathbf{U}$} & \multirow[b]{2}{*}{$\mathbf{P}$} & \multirow[b]{2}{*}{$\mathbf{r}$} \\
\hline & M & SD & M & SD & & & & M & SD & M & SD & & & \\
\hline $\begin{array}{l}\text { Homofobia } \\
\text { Institucional }\end{array}$ & 4,24 & 0,65 & 4,43 & 0,49 & 2801 & 0,05 & 0,16 & 4,33 & 0,52 & 4,47 & 0,71 & 1972,5 & 0,03 & 0,18 \\
\hline Malestar & 4,63 & 0,62 & 4,69 & 0,48 & 2414,5 & 0,76 & 0,02 & 4,66 & 0,47 & 4,67 & 0,76 & 1667 & 0,59 & 0,05 \\
\hline Desviación & 4,79 & 0,79 & 4,91 & 0,32 & 2448,5 & 0,43 & 0,07 & 4,87 & 0,5 & 4,85 & 0,76 & 1623 & 0,58 & 0,05 \\
\hline Identificación & 37,62 & 6,7 & 34,77 & 8,44 & 1859,5 & 0,05 & 0,01 & 35,71 & 7,07 & 39,54 & 8,69 & 1859,5 & 0,39 & $-0,18$ \\
\hline Disfrute & 3,45 & 1,01 & 2,88 & 0,9 & 1805,5 & 0,14 & 0,21 & 3,56 & 0,94 & 4,29 & 0,85 & 1805,5 & 0,00 & $-0,21$ \\
\hline Gusto & 3,59 & 0,89 & 3,8 & 0,88 & 2076 & 0,213 & $-0,11$ & 3,58 & 0,86 & 4,25 & 0,8 & 2076 & 0,00 & $-0,11$ \\
\hline
\end{tabular}

Tal y como se observa, el test U Mann-Whitney revela que existen diferencias significativas entre hombres y mujeres en la puntuación de la subescala homofobia institucional, donde las mujeres tienen puntuaciones más elevadas que los hombres. En este caso, podemos decir que las mujeres tienen una actitud más positiva que los hombres hacia la homofobia institucional. También, existen diferencias estadísticamente significativas entre hombres y mujeres en identificación con los personajes. En este caso, son los hombres los que tienen mayor puntuación que las mujeres, ellos se identifican más que las mujeres con el personaje. La medida del efecto revela que esta diferencia es baja.

Si consideramos las diferencias según condición sexual, existen diferencias significativas en homofobia institucional, disfrute y gusto. Las personas con una orientación sexual normativa tienen puntuaciones más bajas que 


\section{DISERTACIONES}

ESTUDIOS

las que manifiestan una sexualidad no normativa en homofobia institucional, en disfrute y en gusto. La medida del efecto revela que estas diferencias son moderadas. Podemos concluir pues que las lesbianas y los gais tienen una actitud positiva en homofobia institucional y tienen más disfrute y gusto que las personas heterosexuales.

Dado que la actitud hacia la homofobia en general tiene puntuaciones muy elevadas, podemos decir que en la muestra utilizada no existen actitudes negativas hacia las lesbianas en esta serie.

\section{Correlaciones entre MHS-L, identificación, disfrute y gusto}

En la tabla 3 se encuentran las correlaciones entre las subescalas de homofobia, la identificación, el disfrute y el gusto. Tal y como se puede observar, hay relación lineal positiva significativa con la subescala homofobia institucional respecto a las otras variables de interés (identificación, disfrute y gusto). A mayor puntuación en homofobia institucional, más identificación con los personajes, disfrute y gusto. Hemos de tener en cuenta que las puntuaciones de los participantes en general son muy elevadas y eso reduce la variabilidad de las puntuaciones. En el caso de las otras subescalas de MHS-L, no podemos considerar que haya una relación lineal positiva. Aunque malestar tiene una relación estadísticamente significativa con disfrute y gusto, este valor es muy bajo.

Tabla 3. Correlaciones entre MHS-L, identificación, disfrute y gusto

\begin{tabular}{|l|l|l|l|}
\hline & \multicolumn{1}{c|}{ MHS-L } & \multicolumn{1}{c|}{ Desviación } \\
\hline & \multicolumn{1}{|c|}{ Institucional } & \multicolumn{1}{c|}{ Malestar } & $-0,073$ \\
\hline Identificación &, $200^{*}$ &, 102 & 0,108 \\
\hline Disfrute &, $294^{\star *}$ &, $167^{\star}$ & 0,037 \\
\hline Guste &, $345^{\star *}$ &, $176^{\star}$ & \multicolumn{2}{|c|}{} \\
\hline
\end{tabular}

$$
\text { Nota: }{ }^{\star} \mathrm{p}<, 05 ;{ }^{\star \star} \mathrm{p}<, 001
$$

\section{Discusión}

Atendiendo al primer objetivo general, se han obtenido pruebas de validez que confirman la estructura de la escala original MHs-L (Raja \& Stokes, 1998) de tres factores en adultos dentro del contexto español. No obstante, en el contexto español se propone eliminar el ítem 1 de la escala ("Los empresarios deberían proporcionar un seguro médico para las parejas de sus empleadas lesbianas") ya que no representa el contenido de esta cultura. Debido a que la solución factorial no ha convergido, no se aportan evidencias a favor de un factor general que explique la homofobia.

Aunque parte de la discusión se realiza a partir de los resultados de Carvalho (2015), puesto que es el único estudio encontrado en el contexto español que haya abordado la mHs-L en relación con los procesos psicológicos de recepción, es necesario matizar que la puntuación total se ha obtenido a partir de constructos no equivalentes. Mientras que Carvalho (2015) obtiene el grado de homofobia con una puntuación global a partir de la suma de todos los ítems, clasificando los resultados en actitudes positivas, neutras y negativas, en la presente investigación se han analizado los resultados a partir de las tres dimensiones de la escala de los autores originales (Raja \& Stokes, 1998). 


\section{DISERTACIONES}

ESTUDIOS

Estudios de audiencias y recepción: audiencias minoritarias y nuevas mediaciones

ISSN: 1856-9536

Doi: http://dx.doi.org/10.12804/revistas.urosario.edu.co/disertaciones/v11i1

Volumen 11, Número 1 / Enero-junio 2018

Versión PDF para imprimir desde

http://revistas.urosario.edu.co/index.php/disertaciones

Los resultados obtenidos en esta investigación manifiestan diferencias significativas en las actitudes hacia el factor homofobia institucional, mientras que no se detectan diferencias en los otros factores de la MHS-L. Estas diferencias se evidencian tanto en el género como en la orientación sexual, en las que las mujeres y aquellos con una sexualidad no normativa son quienes muestran una actitud más positiva hacia las lesbianas en esta subescala. Por tanto, se confirman parcialmente las hipótesis $\mathrm{H} 1 \mathrm{a}$ y H1b y se obtienen resultados diferentes a los estudios que no encontraron diferencias en la orientación sexual y el género respecto a las actitudes homófobas. También se han obtenido resultados diferentes a los estudios precedentes que afirmaban que las personas son más homofóbicas con los gais y lesbianas de su propio género (Herek \& Capitanio, 1995; Kite \& Whitley, 1996; Kite, 1987).

Respecto al fenómeno de la identificación, los resultados señalan que los hombre se identifican más que las mujeres, aunque de forma muy moderada, mientras que no hay diferencias entre los que manifiestan una sexualidad normativa y no normativa. Esto rechaza completamente las hipótesis $\mathrm{H} 2$ y H3, lo que se enfrenta con la literatura precedente que consideraba que la identificación sería mayor en las mujeres, gais y lesbianas dados los aspecto de resonancia personal y similitud. No obstante, este resultado puede explicarse a partir de la teoría de disposición del afecto y las ideas sugeridas por Soto Sanfiel et al. (2014b), quienes afirman que en la identificación con los personajes prevalecen las acciones, valores y actitudes de la propia configuración del personaje frente a su género u orientación sexual. También invita a continuar explorando el fenómeno de la identificación en relación al género de la audiencia desde métodos más cualitativos que permitan complementar estos resultados.

Por otro lado, se evidencia que los gais y las lesbianas de la muestra han disfrutado más y les ha gustado más que a los heterosexuales el fragmento de la serie presentado, al contrario de los resultados de Soto-Sanfiel et al. (2014b), que sugerían que el disfrute y el gusto no estaba influenciado por la orientación sexual. Finalmente, se ha detectado una relación positiva entre la subescala de homofobia institucional y el disfrute, la identificación y el gusto, por lo que aquellos que han manifestado actitudes más positivas hacia las lesbianas en esta subescala se han identificado más intensamente y han disfrutado y les ha gustado más la serie. Esto solo confirma parcialmente la hipótesis 4 que conforme los resultados de Carvalho (2015) sugería que la persona con una actitud menos homofóbica tendría una mejor experiencia en su conjunto. No obstante, no se puede confirmar por completo esta hipótesis porque en las otras dos subescalas de la homofobia, malestar personal y desviación, no se detectó una relación positiva o negativa con los fenómenos de disfrute, identificación o gusto.

Como ya se ha puesto de manifiesto, a pesar de la creciente representación del universo lésbico en las ficciones audiovisuales, los estudios sobre su recepción y percepción en las audiencias son escasos (González de Garay, 2009; Soto-Sanfiel et al., 2014; Carvalho, 2015). En esta investigación se ha explorado el proceso de la identificación con los personajes, pues se considera que se trata de una variable central para comprender los efectos del entretenimiento (Cohen, 2006; Igartua \& Barrios, 2012). La identificación con los personajes permite explicar el disfrute, la apreciación o el engagement (Busselle \& Bilandzic, 2009; Igartua \& Barrios, 2012; Oliver \& Bartsch, 2010). Además, la identificación con los personajes se considera un factor determinante en la persuasión y el cambio de actitud en las audiencias (Igartua \& Muñiz, 2008). Por todas estas razones se considera que explorar su relación con la recepción de los personajes lésbicos y la homofobia puede ayudar a plantear la función educativa y persuasiva de las ficciones audiovisuales populares. 


\section{DISERTACIONES}

ESTUDIOS

\section{Limitaciones y futuras líneas de investigación}

En líneas generales, puede decirse que los resultados del estudio nos permiten afirmar que la homofobia afecta el proceso de identificación, el disfrute o el gusto de las ficciones audiovisuales protagonizadas por lesbianas. Solamente una subescala de la escala general (formada por tres): homofobia institucional, presenta una relación significativa con los procesos de recepción estudiados. A mayor actitud positiva hacia las lesbianas en esta subescala, mayor disfrute, identificación y gusto. Los datos muestran que los hombres se identifican más que las mujeres y que los gais, y las lesbianas disfrutaron y les gustó más la serie. Por tanto, se sugiere que la correspondencia entre el género del sujeto y el personaje no es determinante en la identificación con los personajes. También, que la orientación sexual influye en el disfrute y el gusto, pero no en la identificación.

Estos resultados abren nuevas líneas de investigación en las que profundizar para encontrar explicaciones. En primer lugar, la solución factorial no convergente obtenida en el modelo 3 presentado en esta investigación puede ser debida al tamaño muestral utilizado en el estudio. Tal y como indica Natesan (2015), los métodos de estimación no bayesianos cuando hay muestras pequeñas en muchas ocasiones generan no convergencia. En futuros estudios, y para evitar entre otros, problemas de convergencia, sería idóneo obtener muestras más grandes para explorar una solución jerárquica que permita obtener una puntuación total.

Desde los datos obtenidos se propone indagar en la relación entre la orientación sexual, el género y el disfrute y el gusto, ya que los resultados refutan parte de la literatura precedente. Otra cuestión a explorar es por qué solo se han detectado diferencias significativas en la subescala de homofobia institucional, pero no en ninguna de las otras dos. Se considera que, en gran medida, estas cuestiones podrían ser estudiadas replicando los análisis en una muestra más amplia y heterogénea que diera un patrón de respuesta más heterogéneo. Una de las limitaciones que se reconocen en este estudio es la utilización de una muestra de conveniencia que ha podido dar lugar a una distribución muy extrema en las respuestas, lo que podría explicar que las actitudes hacia las lesbianas hayan sido tan homogéneas y positivas.

Finalmente, se quiere instar y motivar este tipo de estudios que permiten conocer las consecuencias de la identificación con los personajes en las ficciones. Algunos autores han sugerido que la identificación con los personajes propicia la apertura de nuevos puntos de vista, ayuda a explicar el impacto persuasivo de los contenidos narrativos (Slater \& Rouner, 2002) e influye en los procesos de persuasión narrativa (Igartua \& Barrios, 2012). Por tanto, investigaciones que exploren dichas cuestiones pueden ayudar a conocer el potencial de las ficciones protagonizadas por personajes gais y lesbianas para disminuir las actitudes homofóbicas.

\section{Referencias}

1. Agnew, C. R., Thompson, V. D., Smith, V. A., Gramzow, R. H., \& Currey, D. P. (1993). Proximal and distal predictors of homophobia: Framing the multivariate roots of outgroup rejection. Journal of Applied Social Psychology, 23(24), 2013-2042.

2. Aguero, J., Bloch, L., \& Byrne, D. (1984). The relationships among sexual beliefs, attitudes, experience, and homophobia. Journal of Homosexuality, 10(1-2), 95-107. 


\section{DISERTACIONES}

ESTUDIOS

Estudios de audiencias y recepción: audiencias minoritarias y nuevas mediaciones

ISSN: 1856-9536

Doi: http://dx.doi.org/10.12804/revistas.urosario.edu.co/disertaciones/v11i1

Volumen 11, Número 1 / Enero-junio 2018

Versión PDF para imprimir desde

http://revistas.urosario.edu.co/index.php/disertaciones

3. Bilandzic, H., \& Busselle, R. (2011). Enjoyment of films as a function of narrative experience, perceived realism and transportability. Communications, 36(1), 29-50.

4. Blumenfeld, W. J. (1992). Homophobia: How we all pay the price. Boston: Beacon Press.

5. Busselle, R., \& Bilandzic, H. (2009). Measuring narrative engagement. Media Psychology, 12(4), 321-347.

6. Calvert, S., Murray, K., \& Conger, E. (2004). Heroic Dvo portrayals: What us and Taiwanese adolescents admire and understand. Journal of Applied Developmental, 25(6), 699-716.

7. Carvalho, A. (2015). Influencia de la moralidad en la apreciación, percepción de realismo y disfrute de las narrativas sobre lesbianas. (Tesis doctoral. Universitat Autònoma de Barcelona: Barcelona, España).

8. Chory-Assad, R., \& Cicchirillo, V. (2005). Empathy and affective orientation as predictors of identification with television characters. Communication Research Reports, 22(2), 151-156.

9. Cohen, J. (1988). Statistical power analysis for the behavioral sciences (2nd ed.). Hillsdale: Lawrence Earlbaum Associates.

10. Cohen, J. (2001). Defining identification: A theoretical look at the identification of audiences with media characters. Mass Communication y Society, 4(3), 245-264.

11. Cohen, J. (2006). Audience identification with media characters. En J. Bryant, \& P. Vorderer (Eds.), Psychology of Entertainment (pp. 183-197). Mahwah: Lawrence Erlbaum Associates.

12. Collier, N., Lumadue, C., \& Wooten, H. (2009). Buffy the vampire slayer and Xena: Warrior Princess. Reception of the texts by a sample of lesbian fans and web site users. Journal of Homosexuality, 56(5), 575-609.

13. Davis, M., \& Hull, J. (1987). Emotional reactions to dramatic film stimuli: the influence of cognitive and emotional empathy. Journal of Personality, 52(1), 126-133.

14. Eyal, K., \& Rubin, A. (2003). Viewer aggression and homophily, identification, and parasocial relationships with television characters. Journal of Broadcasting and Electronic Media, 47(1), 77-98.

15. Faderman, L. (1985). Surpassing the love of men. Londres: Women's Press.

16. Fritz, C. O., Morris, P. E., \& Richler, J. J. (2012). Effect size estimates: Current use, calculations, and interpretation. Journal of Experimental Psychology: General, 141(1), 2-18.

17. González de Garay, B. (2009). Ficción online frente a ficción televisiva en la nueva sociedad digital: diferencias de representación del lesbianismo entre las series españolas para televisión. Icono, 14(2), 3-15.

18. Hall, M., Kitzinger, C., Loulan, J., \& Perkins, R. (1992). Lesbian psychology, lesbian politics. Feminism \& Psychology, 2(1), 7-25.

19. Hansen, G. (1982). Measuring prejudice against homosexuality (homosexism) among college students: A new scale. The Journal of Social Psychology, 117(2), 233-236.

20. Herek, G., \& Capitanio, J. (1995). Black heterosexuals' attitudes toward lesbians and gay men in the United States. Journal of Sex Research, 32(2), 95-105.

21. Hill, D., \& Willoughby, B. (2005). The development and validation of the genderism and transphobia scale. Sex Roles, 53(7-8), 531-544.

22. Hoffner, C., \& Cantor, J. (1991). Perceiving and responding to mass media characters. En Bryant y Zillmann (Eds.), Responding to the Screen: Reception and Reaction Processes (63-101). New Jersey: Lawrence Erlbaum.

23. Hudson, W., \& Ricketts, W. (1980). A strategy for the measurement of homophobia. Journal of Homosexuality, 5(4), 357-372. 


\section{DISERTACIONES}

ESTUDIOS

Estudios de audiencias y recepción: audiencias minoritarias y nuevas mediaciones

ISSN: 1856-9536

Doi: http://dx.doi.org/10.12804/revistas.urosario.edu.co/disertaciones/v11i1

Volumen 11, Número 1 / Enero-junio 2018

Versión PDF para imprimir desde

http://revistas.urosario.edu.co/index.php/disertaciones

24. Ibiti, A. (2011). Identificación y disfrute de mujeres homosexuales en la recepción de personajes de lesbianas (una aproximación cualitativa). (Tesis de maestría, Universitat Autònoma de Barcelona, Bellaterra, Barcelona, España).

25. Ibiti, A. (2013). ¿Qué les gusta a las lesbianas? Revista Orbis, Revista Científica Ciencias Humanas, 8(24), 15-35.

26. Igartua, J. J. (2007). Persuasión narrativa. El papel de la identificación con los personajes a través de las culturas. Alicante: Editorial Club Universitario.

27. Igartua, J. J., Barrios, I., \& Piñeiro, V. (2011). Persuading people through controversial movies: processes and mechanisms of narrative persuasion. Comunicación presentada en el 61th Annual Conference of the International Communication Association (ICA). Boston, EE.uU.

28. Igartua, J.J., \& Barrios, I. (2012). Changing real-world beliefs with controversial movies: Processes and mechanisms of narrative persuasion. Journal of Communication, 62(3), 514-531.

29. Igartua, J.J., \& Muñiz, C. (2008). Identificación con los personajes y disfrute ante largometrajes de ficción. Una investigación empírica. Comunicación y Sociedad, 11(1), 25-52.

30. Igartua, J.J, \& Páez, D. (1998). Validez y fiabilidad de una escala de empatía e identificación con los personajes. Psicothema, 10, 423-436.

31. Kite, M. (1987). Gender belief systems: Homosexuality and the implicit inversion theory. Psychology of Women Quarterly, 11(1), 83.

32. Kite, M., \& Whitley, B. (1996). Sex differences in attitudes toward homosexual persons, behaviors, and civil rights a meta-analysis. Personality and Social Psychology Bulletin, 22(4), 336-353.

33. LaMar, L., \& Kite, M. (1998). Sex differences in attitudes toward gay men and lesbians: A multidimensional perspective. Journal of Sex Research, 35(2), 189-196.

34. Larsen, K., Reed, M., \& Hoffman, S. (1980). Attitudes of heterosexuals toward homosexuality: A Likert-type scale and construct validity. Journal of Sex Research, 16(3), 245-257.

35. Lingiardi, V., Falanga, S., \& D’Augelli, A. (2005). The evaluation of homophobia in an Italian sample. Archives of Sexual Behaviour, 34(1), 81-93.

36. Linné, O. (1975). Identifying with television characters. Journal of Communication, 25(4), 51-55.

37. Maccoby, E., \& Wilson, W. (1957). Identification and observational learning from films. The Journal of Abnormal and Social, 55(1), 76-87.

38. Natesan, P. (2015). Comparing interval estimates for small sample ordinal cFa models. Frontiers in Psychology,6, 1-14.

39. Oliver, M. B., \& Bartsch, A. (2010). Appreciation as audience response: Exploring entertainment gratifications beyond hedonism. Human Communication Research, 36(1), 53-81.

40. Raja, S., \& Stokes, J. (1998). Assessing attitudes toward lesbians and gay men: The modern homophobia scale. International Journal of Sexuality and Gender Studies, 3(2), 113-134.

41. Rodríguez-Castro, Y., Lameiras-Fernández, M., Carrera-Fernández, V., \& Vallejo-Medina, P. (2013). Validación de la Escala de Homofobia Moderna en una muestra de adolescentes. Anales de Psicología. 29(2), 523-533. 


\section{DISERTACIONES}

ESTUDIOS

42. Rosseel, Y. (2012). LavaAn: An R package for structural equation modeling. Journal of Statistical Software, 48(2), 1-36.

43. SemTools Contributors. (2016). semTools: Useful tools for structural equation modeling. R package version 0.4.11.

44. Slater, M., \& Rouner, D. (2002). Entertainment, education and elaboration likelihood: Understanding the processing of narrative persuasion. Communication Theory, 12(2), 173-191.

45. Smith, K. (1971). Homophobia: A tentative personality profile. Psychological Reports, 29(3), 1091-1094.

46. Soto-Sanfiel, M.T., Aymerich-Franch, L., \& Ribes Guàrdia, F. (2010). Impacto de la interactividad en la identificación con los personajes de ficciones. Psicothema, 22(4), 822-827.

47. Soto-Sanfiel, M. T.; Ibiti, A., Palencia-Villa, R. M., \& Velásquez, L. (2011). Recepción de personajes lésbicos por audiencias de distintas orientaciones sexuales manifiestas. Informe técnico. Barcelona: Intitut Català de les Dones.

48. Soto-Sanfiel, M. T., Palencia-Villa, R. M., \& Ibiti, A. (2014a). The role of sexual orientation and gender in the appreciation of lesbian narratives in media. The French Journal of Media and Media Representations in the English-Speaking World, (5).

49. Soto-Sanfiel, M., Ibiti, A., \& Palencia-Villa. (2014b). La identificación con personajes de lesbianas: recepción de audiencias heterosexuales y homosexuales desde una aproximación metodológica mixta. Revista Latina de Comunicación Social, 69, 275-306.

50. Soto-Sanfiel, M. T., \& Ibiti A. (2016). Lesbian sex in mainstream cinema and audience enjoyment. Sexuality \& Culture, 20(3), 555-578.

51. Vorderer, P., Klimmt, C., \& Ritterfeld, U. (2004). Enjoyment: At the heart of media entertainment. Communication Theory, 14(4), 388-408.

52. Weingberg, G. (1973). The good guys, the bad guys, and the gay guys. Contemporary Sociology, 2(1), 3-13.

53. Wied, M. De, Zillmann, D., \& Ordman, V. (1994). The role of empathic distress in the enjoyment of cinematic tragedy. Poetics, 23(1-2), 91-106.

54. Wilson, T., \& Bickley, I. (1993). Watching television: Hermeneutics, reception and popular culture. Cambridge: Polity Press.

55. Wright, J., Adams, H., \& Bernat, J. (1999). Development and validation of the homophobia scale. Journal of Psychopathology and Behavioral Assessment, 21(4), 337-347.

56. Wylie, L., \& Forest, J. (1992). Religious fundamentalism, right-wing authoritarianism and prejudice. Psychological Reports, 71(3), 1291-1298.

57. Zinbarg, R. E., Revelle, W., Yovel, I., \& Li, W. (2005). Cronbach's $\alpha$, Revelle's $\beta$, and Mcdonald's $\omega H$ : their relations with each other and two alternative conceptualizations of reliability. Psychometrika, 70(1), 123-133. 